\title{
Enhancement of Chondrogenesis in Hypoxic Precondition Culture: A Systematic Review
}

\author{
Sholahuddin Rhatomy ${ }^{1,2,3 *}$, Riky Setyawan ${ }^{3}$, Michael Aaron Romulo ${ }^{4}$ \\ ${ }^{1}$ Department of Orthopaedics and Traumatology, Faculty of Medicine, Public Health and Nursing, Universitas Gadjah Mada, \\ Yogyakarta, Indonesia; ${ }^{2}$ Department of Orthopaedics and Traumatology, Sport and Adult Reconstructive Division, Dr. Soeradji \\ Tirtonegoro General Hospital, Klaten, Indonesia; ${ }^{3}$ Department of Orthopaedics and Traumatology, Faculty of Medicine \\ Universitas Indonesia, Cipto Mangunkusumo General Hospital, Jakarta, Indonesia; ${ }^{4}$ Soeradji Tirtonegoro Sport Center and \\ Research Unit, Dr. Soeradji Tirtonegoro General Hospital, Klaten, Indonesia
}

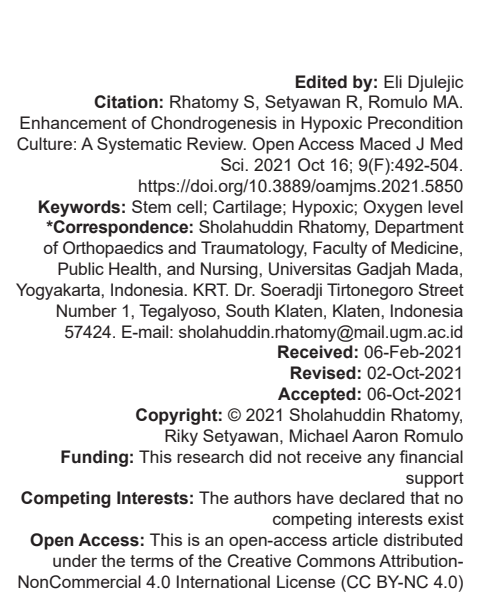

Abstract

BACKGROUND: Cartilage tear has begun to be treated with stem cells. However, stem cell oxygen level culture has not been evaluated for the best environment to enhance chondrogenesis.

AIM: The purpose of this review is to focus on the hypoxic oxygen level of stem cells culture as a treatment for cartilage tear.

METHODS: A literature search was systemically conducted on PubMed (MEDLINE), OVID, EMBASE, the Cochrane Library, Scopus, Web of Science, Science Direct, Wiley Online Library, Google Scholar, and bibliography of selected articles with the terms ("culture") AND ("stem cell" OR "mesenchymal stem cell" OR "MSC") AND ("hypoxic" OR "hypoxia") AND ("cartilage" OR "chondro*") as the main keywords. A total of 438 articles were reviewed. Thirty-six articles were considered relevant for this systematic review.

RESULTS: The result of this review supports stimulation effects of hypoxic oxygen level stem cell culture in chondrogenesis process. Most studies used $5 \%$ oxygen concentration for culture, both of in vivo and in vitro studies. Due to the heterogeneity nature of the included studies, meta-analysis was unable to be conducted.

CONCLUSION: Hypoxia state seems to play an important role in chondrocytes proliferation, differentiation, and matrix production.

\section{Introduction}

Cartilage has many important roles to support the normal joint function. It provides the gliding between two bone surfaces and as shock-absorber [1]. Cartilage is incapable to repair and regenerate once it is damaged [2]. Treatment of choice in cartilage damage varies from pharmacologic therapy to surgery. The latest surgical therapy methods are marrow stimulating technique, osteochondral transplantation, and autologous chondrocyte implantation [2], [3], [4]. Cell-based therapy is currently used to treat focal cartilage defects [5].

Stem-cell-based therapy has been used as an additional treatment because of its self-renewal properties, differentiation potentials, and immunemodulatory activities [6]. Stem cells can generate more fibrous cartilage to construct its biomechanical property and have higher durability [4]. After a 6-month follow-up, hyaline cartilage was regenerated after Mesenchymal Stem Cells (MSCs) were injected into the joint [7].
Stem cell culture is done to collect enough cells for transplant process. The previous researches did not consider the oxygen level condition in stem cell culture. Room air oxygen level $(21 \%)$ is widely used to culture stem cells [8], [9]. Normally, cartilage is relatively avascular with a range of $1-7 \%$ of oxygen concentration [9]. Hypoxic state can induce sexdetermining region Y-box9 (SOX9) expression that is an important transcription factor for chondrogenesis [9] Stem cell proliferation and multipotency are maintained in hypoxic condition [5], [9], [10], [11]. Hypoxic state also increases extra-cellular matrix synthesis by chondrocytes [9].

However, there is still not enough data to confirm the level of hypoxic condition medium for stem cell culture. A systematic review from existing preclinical studies is needed to consider the safety and efficacy, and to guide future studies. The main purpose of this review is to summarize the in vitro studies regarding the hypoxic level of stem cell culture as a treatment for any cartilage damages. 


\section{Methods}

\section{Eligibility criteria} the following:

The inclusion criteria for this review consist of

- $\quad$ Study design: Controlled laboratory study (in vitro study)

- $\quad$ Study group: Stem cell isolation from human or animals

- Interventions: Any application of hypoxic level condition to the study groups

- Outcomes: Main outcomes were any chondrogenic marker, cell size, and gene expression

- $\quad$ Language: English.

Non-English studies, duplicates, review articles, and irrelevant articles were excluded from the study.

\section{Literature search and study selection}

A comprehensive search was performed in accordance with the Preferred Reporting Items for
Systematic Reviews and Meta-Analyses (PRISMA) guidelines [12]. The search was conducted from 9 sources including PubMed (MEDLINE), OVID, EMBASE, the Cochrane Library, Scopus, Web of Science, Science Direct, Wiley Online Library, Google Scholar, and bibliography of selected articles on July 1,2020 . The date range was restricted to all studies conducted through July 1, 2020. The term ("culture") AND ("stem cell" OR "mesenchymal stem cell" OR "MSC") AND ("hypoxic" OR "hypoxia") AND ("cartilage" OR "chondro*") was used as the search keyword.

Two authors (R.S. and S.R.) independently screened the title and abstracts for eligibility by reading the full texts, therefore using it to apply the inclusion and exclusion criteria. Additional searches were done to further include studies mentioned in the reference lists. Discussion was done to resolve any disagreements between the two authors.

\section{risk of bias \\ Methodological quality assessment and}

ROBIS systematic review tool was used to assess the methodological quality of the included

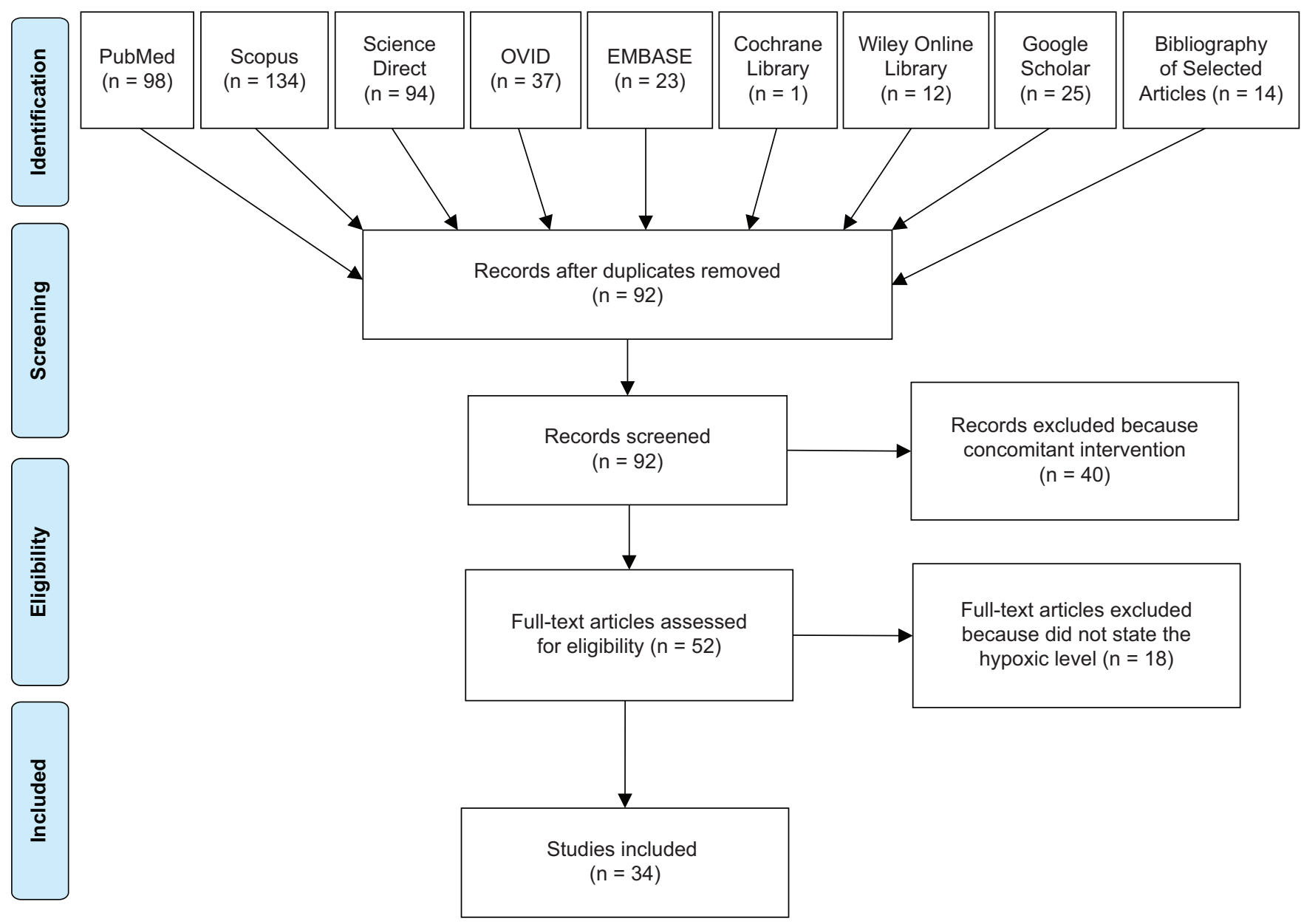

Figure 1: Flow chart of study process selection 
Table 1: In vitro study result

\begin{tabular}{|c|c|c|c|c|c|c|c|}
\hline Author & Type of MSC (Donor) & $\begin{array}{l}\text { Donor } \\
\text { characteristics }\end{array}$ & Cells preparation & $\begin{array}{l}\text { Intervention to the } \\
\text { main group }\end{array}$ & Control(s) & Duration & Scores/Results \\
\hline $\begin{array}{l}\text { Adesida } \\
\text { et al. (2012) }\end{array}$ & BM-MSC (Human) & $\begin{array}{l}\text { lliac crest of } 6 \\
\text { donors } \\
(1 \text { female } \\
34 \text { y.o. and } \\
5 \text { male } \\
43-62 \text { y.o.) }\end{array}$ & $\begin{array}{l}\text { a-MEM supplemented with } 10 \% \\
\text { heat inactivated FBS, penicillin- } \\
\text { streptomycin, } 4 \text {-(2-hydroxyethyl)-1- } \\
\text { piperazineethanesulfonic acid (HEPES), } \\
\text { sodium pyruvate and } 5 \mathrm{ng} / \mathrm{ml} \text { bFGF or } \\
\text { FGF2 at } 37^{\circ} \mathrm{C} \text { with } 5 \% \mathrm{CO}_{2}\end{array}$ & $\begin{array}{l}\text { Hypoxia (oxygen } \\
\text { tension } 3 \% \text { ) }\end{array}$ & $\begin{array}{l}\text { Normoxia (oxygen } \\
\text { tension } 21 \% \text { ) }\end{array}$ & $\begin{array}{l}14 \text { days; } \\
21 \text { days }\end{array}$ & 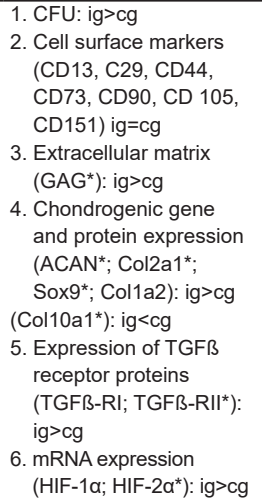 \\
\hline $\begin{array}{l}\text { Bae et al. } \\
(2018)\end{array}$ & SDSC (Human) & $\begin{array}{l}\text { Synovium tissue } \\
\text { from } 5 \text { female } \\
\text { osteoarthritis } \\
\text { patients } \\
\text { (66-72 y.o.) with } \\
4^{\text {th }} \text { gradeKellgren } \\
\text { Lawrence } \\
\text { classification } \\
\text { and undergone } \\
\text { TKA }\end{array}$ & $\begin{array}{l}\text { LG-DMEM with } 10 \% \text { fetal bovine serum } \\
\text { (FBS) and } 1 \% \text { penicillin/streptomycin/ } \\
\text { amphotericin at } 37^{\circ} \mathrm{C} \text { with } 5 \% \mathrm{CO}_{2}\end{array}$ & $\begin{array}{l}\text { Hypoxia (oxygen } \\
\text { tension } 5 \% \text { ) }\end{array}$ & $\begin{array}{l}\text { Normoxia (oxygen } \\
\text { tension } 21 \% \text { ) }\end{array}$ & $\begin{array}{l}14 \text { days and } \\
21 \text { days }\end{array}$ & 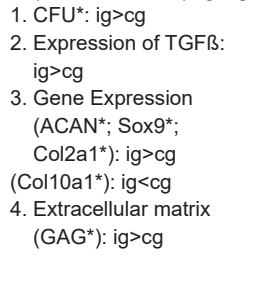 \\
\hline $\begin{array}{l}\text { Bornes } \\
\text { et al. } \\
(2015)\end{array}$ & BM-MSC (Bovine) & $\begin{array}{l}\text { Iliac crest from } \\
6 \text { skeletally } \\
\text { mature, female } \\
\text { Suffolk sheep } \\
\text { with mean age } \\
3.3 \pm 0.8 \text { years }\end{array}$ & $\begin{array}{l}\text { a-MEM supplemented with } 10 \% \\
\text { heat inactivated FBS, penicillin- } \\
\text { streptomycin, } 4-(2 \text {-hydroxyethyl)-1- } \\
\text { piperazineethanesulfonic acid (HEPES), } \\
\text { sodium pyruvate and } 5 \mathrm{ng} / \mathrm{ml} \text { bFGF or } \\
\text { FGF2 at } 37^{\circ} \mathrm{C} \text { with } 5 \% \mathrm{CO}_{2}\end{array}$ & $\begin{array}{l}\text { Hypoxia (oxygen } \\
\text { tension } 3 \% \text { ) }\end{array}$ & $\begin{array}{l}\text { Normoxia (oxygen } \\
\text { tension } 21 \% \text { ) }\end{array}$ & 14 days & $\begin{array}{l}\text { 1. } C F U^{*} \text { : ig<cg } \\
\text { 2. Gene Expression } \\
\text { (ACAN, Col1, Col2, Col10, } \\
\text { COMP) ig=cg } \\
\text { 3. Extracellular } \\
\text { matrix (GAG*, DNA } \\
\text { quantification): ig>cg } \\
\text { 4. Cell scaffold construct } \\
\text { size*: ig >cg }\end{array}$ \\
\hline $\begin{array}{l}\text { Cicione } \\
\text { et al. (2013) }\end{array}$ & BM-MSC (Human) & $\begin{array}{l}\text { Three patients } \\
\text { who underwent } \\
\text { total hip } \\
\text { replacement } \\
\text { with mean age } \\
64 \text { year }\end{array}$ & $\begin{array}{l}\text { DMEM supplemented with } 20 \% \text { FBS and } \\
1 \% \text { penicillin-streptomycin with } 5 \% \mathrm{CO}_{2}\end{array}$ & $\begin{array}{l}\text { Severe Hypoxia } \\
\text { (oxygen tension 1\%) }\end{array}$ & $\begin{array}{l}\text { Normoxia (oxygen } \\
\text { tension } 21 \% \text { ) }\end{array}$ & 14 days & $\begin{array}{l}\text { 1. Gene Expression } \\
\text { (ACAN, Col1): negative } \\
\text { in cg } \\
\text { (Sox9, Col2a1): ig<cg }\end{array}$ \\
\hline $\begin{array}{l}\text { Duval } \\
\text { et al. } \\
(2012)\end{array}$ & BM-MSC (Human) & $\begin{array}{l}\text { Iliac crest of } \\
\text { adult donors } \\
\text { (ages } 54-75 \text { y.o. } \\
\text { with median } \\
68 \text { y.o.) }\end{array}$ & $\begin{array}{l}\text { a-MEM supplemented with } 10 \% \text { fetal calf } \\
\text { serum, } 2 \mathrm{mM} \text { L-glutamine, } 1 \mathrm{ng} / \mathrm{ml} \mathrm{FGF-2,} \\
\text { and antibiotics }\end{array}$ & $\begin{array}{l}\text { Hypoxia (oxygen } \\
\text { tension } 5 \% \text { ) }\end{array}$ & $\begin{array}{l}\text { Normoxia (oxygen } \\
\text { tension } 21 \% \text { ) }\end{array}$ & 7 days & 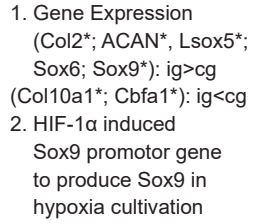 \\
\hline $\begin{array}{l}\text { Felka } \\
\text { et al. (2009) }\end{array}$ & BM-MSC (Human) & $\begin{array}{l}\text { Twenty- } \\
\text { eight patient } \\
\text { undergoing total } \\
\text { hip replacement } \\
\text { with age range } \\
\text { from } 45 \text { to } \\
83 \text { y.o. }\end{array}$ & $\begin{array}{l}\text { LG-DMEM supplemented with } 5 \% \text { human } \\
\mathrm{FFP}, 10^{8} / \mathrm{ml} \text { platelets, } 2 \mathrm{mM} \text { glutamine, } \\
1000 \mathrm{IU} \text { heparin sodium, } 100 \mathrm{U} / \mathrm{ml} \\
\text { penicillin, and } 100 \mathrm{mg} / \mathrm{ml} \text { streptomycin at } \\
37^{\circ} \mathrm{C} \text { with } 5 \% \mathrm{CO}_{2}\end{array}$ & $\begin{array}{l}\text { Hypoxia (oxygen } \\
\text { tension } 2 \% \text { ) }\end{array}$ & $\begin{array}{l}\text { Normoxia (oxygen } \\
\text { tension } 21 \% \text { ) }\end{array}$ & 28 days & $\begin{array}{l}\text { 1. IL-1ß expression: ig>cg } \\
\text { 2. dimension size of } \\
\text { cartilage: ig>cg } \\
\text { 3. Gene expression } \\
\left(\text { Col1a2*; Col2a } 1^{*} ;\right. \\
\text { Col10*; ACAN*; } \\
\text { CD-RAP*, Sox6*; } \\
\text { Sox9*; BMP-2*): ig>cg }\end{array}$ \\
\hline $\begin{array}{l}\text { Gale } \\
\text { et al. (2019) }\end{array}$ & $\begin{array}{l}\text { SM-MSC and } \\
\text { BM-MSC (Horse) }\end{array}$ & $\begin{array}{l}\text { Synovium was } \\
\text { harvested in } \\
\text { standing horses } \\
\text { or during } \\
\text { arthroscopic } \\
\text { procedure in } 5 \\
\text { horses }\end{array}$ & N/A & $\begin{array}{l}\text { Hypoxia (oxygen } \\
\text { tension } 5 \% \text { ) }\end{array}$ & $\begin{array}{l}\text { Normoxia (oxygen } \\
\text { tension } 21 \% \text { ) }\end{array}$ & 28 days & $\begin{array}{l}\text { 1. Extracellular matrix } \\
\text { BM-MSC (GAG, GAG/ } \\
\text { DNA): ig>cg } \\
\text { SM-MSC (GAG, DNA): } \\
\text { ig<cg } \\
\text { 2. Gene Expression } \\
\text { BM-MSC (Sox9; ACAN; } \\
\text { Col2b; Col10a1): ig>cg } \\
\text { SM-MSC (Sox9; Col2b): ig> } \\
\text { cg; (ACAN; Col10a1): ig<cg }\end{array}$ \\
\hline $\begin{array}{l}\text { Galeano- } \\
\text { Garces } \\
\text { et al. (2016) }\end{array}$ & $\begin{array}{l}\text { AMSC and } \\
\text { chondrocyte(Human) }\end{array}$ & $\begin{array}{l}\text { Lipoaspiration } \\
\text { was obtained } \\
\text { from } 3 \\
\text { consenting } \\
\text { healthy donors } \\
\text { Human primary } \\
\text { chondrocytes } \\
\text { were obtained } \\
\text { from healthy } \\
\text { donors } \\
\text { undergoing } \\
\text { amputation } \\
\text { procedures for } \\
\text { congenital limb } \\
\text { deformity }\end{array}$ & $\begin{array}{l}\text { Advanced MEM supplemented with } 10 \% \\
\text { FBS and } 1 \% \text { penicillin/streptomycin at } \\
37^{\circ} \mathrm{C} \text { with } 5 \% \mathrm{CO}_{2}\end{array}$ & $\begin{array}{l}\text { Hypoxia (oxygen } \\
\text { tension } 2 \% \text { ) }\end{array}$ & $\begin{array}{l}\text { Normoxia (oxygen } \\
\text { tension } 21 \% \text { ) }\end{array}$ & 14 days & 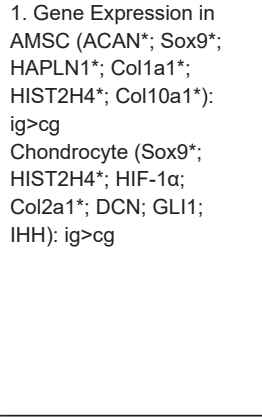 \\
\hline
\end{tabular}


Table 1: (Continued)

\begin{tabular}{|c|c|c|c|c|c|c|c|}
\hline Author & Type of MSC (Donor) & $\begin{array}{l}\text { Donor } \\
\text { characteristics }\end{array}$ & Cells preparation & $\begin{array}{l}\text { Intervention to the } \\
\text { main group }\end{array}$ & Control(s) & Duration & Scores/Results \\
\hline $\begin{array}{l}\text { Gomez- } \\
\text { Leduc et al. } \\
\text { (2017) }\end{array}$ & UCB-MSC (Human) & $\begin{array}{l}\text { Samples } \\
\text { collected at } \\
\text { Obstetrics and } \\
\text { Gynecology Unit } \\
\text { from normal } \\
\text { delivery cases } \\
\text { with the informed } \\
\text { consent from } \\
\text { mothers }\end{array}$ & $\begin{array}{l}\text { LG-DMEM supplemented with } 20 \% \text { fetal } \\
\text { calf serum, } 10^{7} \mathrm{M} \text { dexamethasone and } \\
\text { incubated at } 37^{\circ} \mathrm{C} \text { in a humidified } 5 \% \mathrm{CO}_{2} \\
\text { atmosphere }\end{array}$ & $\begin{array}{l}\text { Hypoxia (oxygen } \\
\text { tension }<5 \% \text { ) }\end{array}$ & $\begin{array}{l}\text { Normoxia (oxygen } \\
\text { tension } 21 \% \text { ) }\end{array}$ & $7,14,21$ days & $\begin{array}{l}\text { 1. Chondrogenesis occurs } \\
\text { in the presence of } \\
\text { BMP-2 and TGF- } B 1 \text { : } \\
\text { ig=cg } \\
\text { 2. Gene Expression } \\
\text { (Col1a1; Col2a1; } \\
\text { Col10a1, MMP-13): } \\
\text { ig<cg }\end{array}$ \\
\hline $\begin{array}{l}\text { Gong } \\
\text { et al. (2017) }\end{array}$ & MSC (Murine) & $\begin{array}{l}\text { The murine } \\
\text { mesenchymal } \\
\text { cell line } \\
\text { C3H10T1/2 } \\
\text { was purchased } \\
\text { from ATCC } \\
\text { (Manassas, VA, } \\
\text { USA) }\end{array}$ & $\begin{array}{l}\text { DMEM supplemented with } 10 \% \text { FBS at } \\
37^{\circ} \mathrm{C} \text { in a humidified } 5 \% \mathrm{CO}_{2} \text { atmosphere }\end{array}$ & $\begin{array}{l}\text { Hypoxia (oxygen } \\
\text { tension } 2 \% \text { ) }\end{array}$ & $\begin{array}{l}\text { Normoxia (oxygen } \\
\text { tension } 21 \% \text { ) }\end{array}$ & 14 days & $\begin{array}{l}\text { 1. Gene Expression } \\
(\text { Sox9*; Col10a1*; } \\
\left.\text { Col2a1 }{ }^{*}, \text { ACAN }^{*}\right): \text { ig }>c g \\
\text { 2. Reduction of miR-124*: } \\
\text { ig }<\text { cg }\end{array}$ \\
\hline $\begin{array}{l}\text { Henrionnet } \\
\text { et al. (2017) }\end{array}$ & BM-MSC (Human) & $\begin{array}{l}\text { Six patients } \\
(3 \text { men and } \\
3 \text { women) } \\
\text { undergoing total } \\
\text { hip arthroplasty } \\
\text { with mean age } \\
64.8 \pm 6.3 \text { y.o. }\end{array}$ & $\begin{array}{l}\text { LG-DMEM supplemented with } 10 \% \text { FBS, } \\
1 \% \text { glutamine, } 1 \% \text { penicillin-streptomycin } \\
\text { and } 1 \mathrm{ng} / \mathrm{ml} \text { bFGF at } 37^{\circ} \mathrm{C} \text { in a humidified } \\
5 \% \mathrm{CO}_{2} \text { atmosphere }\end{array}$ & $\begin{array}{l}\text { Hypoxia (oxygen } \\
\text { tension } 5 \% \text { ) }\end{array}$ & $\begin{array}{l}\text { Normoxia (oxygen } \\
\text { tension } 21 \% \text { ) }\end{array}$ & 14,28 days & 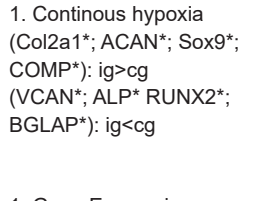 \\
\hline $\begin{array}{l}\text { Huang } \\
\text { et al. (2017) }\end{array}$ & $\begin{array}{l}\text { Human articular } \\
\text { chondrocyte; hMSC; } \\
\text { co-culture hAC/ } \\
\text { hMSC (Human) }\end{array}$ & $\begin{array}{l}\text { Human primary } \\
\text { chondrocytes } \\
\text { were derived } \\
\text { from healthy } \\
\text { looking and } \\
\text { full thickness } \\
\text { cartilage, and } \\
\text { dissected from } \\
\text { knee biopsies } \\
\text { of three patients } \\
\text { (age: } 60 \pm 3 \text { y.o.) } \\
\text { undergoing } \\
\text { total knee } \\
\text { replacement } \\
\text { hMSCs were } \\
\text { isolated } \\
\text { from human } \\
\text { bone marrow } \\
\text { aspirates }\end{array}$ & $\begin{array}{l}\text { hAC: DMEM supplemented with } 10 \% \\
\text { FBS, } 1 \times \text { non-essential amino acids, } \\
\text { ascorbic acid } 2 \text {-phosphate }(0.2 \mathrm{mM}) \text {, } \\
\text { proline }(0.4 \mathrm{mM}) \text {, penicillin }(100 \mathrm{U} / \mathrm{mL}) \\
\text { and streptomycin }(100 \mu \mathrm{g} / \mathrm{mL}) \mathrm{hMSC} \text { : } \\
\text { a-MEM supplemented with } 10 \% \mathrm{FBS} \text {, } \\
1 \% \mathrm{~L} \text {-glutamax, ascorbic acid }(0.2 \mathrm{mM}) \text {, } \\
\text { penicillin }(100 \mathrm{U} / \mathrm{mL}), \text { streptomycin } \\
(100 \mu \mathrm{g} / \mathrm{mL}) \text { and bFGF }(1 \mathrm{ng} / \mathrm{mL})\end{array}$ & $\begin{array}{l}\text { Hypoxia (oxygen } \\
\text { tension } 2.5 \% \text { ) }\end{array}$ & $\begin{array}{l}\text { Normoxia (oxygen } \\
\text { tension } 21 \% \text { ) }\end{array}$ & 35 days & 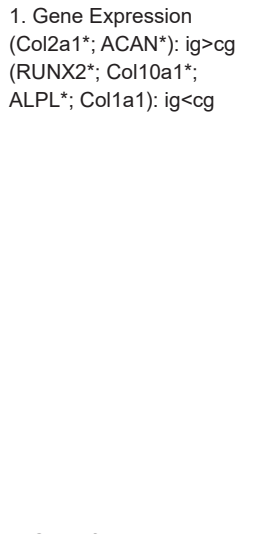 \\
\hline $\begin{array}{l}\text { Hung } \\
\text { et al. (2011) }\end{array}$ & BM-MSC (Human) & $\begin{array}{l}\text { lliac crest of } 15 \\
\text { healthy donors }\end{array}$ & $\begin{array}{l}\text { IMDM and } 10 \% \text { FBS supplemented with } \\
10 \mathrm{ng} / \mathrm{ml} \mathrm{FGF} 2,100 \mathrm{U} \text { penicillin, } 1000 \mathrm{U} \\
\text { streptomycin, and } 2 \mathrm{mM} \text { L-glutamine }\end{array}$ & $\begin{array}{l}\text { Hypoxia (oxygen } \\
\text { tension } 1 \% \text { ) }\end{array}$ & $\begin{array}{l}\text { Normoxia (oxygen } \\
\text { tension } 21 \% \text { ) }\end{array}$ & 28 days & $\begin{array}{l}\text { 1. Size of pallets: ig<cg } \\
\text { 2. Mature chondrocyte } \\
\text { morphology: ig<cg } \\
\text { 3. Gene Expression } \\
\left(\text { Col2a1*; COMP*; }^{*} \text {; }\right. \\
\text { ACAN*): ig<cg }^{*} \text { ig }\end{array}$ \\
\hline $\begin{array}{l}\text { Kalpakci } \\
\text { et al. (2014) }\end{array}$ & DIAS (Goat) & $\begin{array}{l}\text { Full-thickness } \\
\text { skins from the } \\
\text { abdomens of } \\
\text { seven adult } \\
\text { goats were } \\
\text { obtained from a } \\
\text { local abattoir }\end{array}$ & $\begin{array}{l}\text { DMEM and } 10 \% \text { FBS supplemented with } \\
4.5 \mathrm{~g} / \mathrm{L} \text { glucose and L-glutamine, } 1 \% \\
\text { penicillin/streptomycin/fungizone, and } 1 \% \\
\text { non-essential amino acids }\end{array}$ & $\begin{array}{l}\text { Hypoxia (oxygen } \\
\text { tension } 5 \% \text { ) }\end{array}$ & $\begin{array}{l}\text { Normoxia (oxygen } \\
\text { tension } 20 \% \text { ) }\end{array}$ & 14 days & $\begin{array}{l}\text { 1. CFU*: ig<cg } \\
\text { 2. Cell growth*: ig<cg } \\
\text { 3. Total Collagen } \\
\text { production*: ig }>c \mathrm{cg} \\
\text { 4. Collagen type II: ig>cg } \\
\text { 5. GAG content*: ig }>\mathrm{cg} \\
\text { 6. Histological evaluation } \\
\text { (Collagen type } 1 \\
\left.\text { staining }^{\star}\right): \text { ig }>\mathrm{cg}\end{array}$ \\
\hline $\begin{array}{l}\text { Kanichai } \\
\text { et al. (2008) }\end{array}$ & BM-MSC (Rat) & $\begin{array}{l}\text { Three-month } \\
\text { old Wistar rats } \\
\text { ( } 250-350 \mathrm{~g}) \text { with } \\
\text { the femur and } \\
\text { tibia were cut at } \\
\text { both epiphyses } \\
\text { and marrow } \\
\text { was flushed } \\
\text { into a } 50 \mathrm{ml} \\
\text { tube using } 5 \mathrm{ml} \\
\text { supplemented } \\
\text { DMEM and } \\
\text { a } 25 \text {-gauge } \\
\text { needle. }\end{array}$ & $\begin{array}{l}\text { DMEM supplemented with } 10 \% \mathrm{FBS} \\
100 \mathrm{U} / \mathrm{ml} \text { penicillin/streptomycin; } 2 \mathrm{mM} \\
\text { Glutamax; } 1 \mathrm{mM} \text { L-glutamine and } 1 \% \\
\text { non-essential amino acids at } 37^{\circ} \mathrm{C} \text { in a } \\
\text { humidified } 5 \% \mathrm{CO}_{2} \text { atmosphere }\end{array}$ & $\begin{array}{l}\text { Hypoxia (oxygen } \\
\text { tension } 2 \% \text { ) }\end{array}$ & $\begin{array}{l}\text { Normoxia (oxygen } \\
\text { tension } 20 \% \text { ) }\end{array}$ & 21 days & 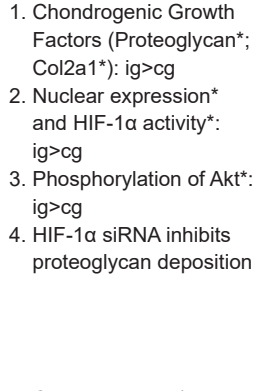 \\
\hline $\begin{array}{l}\text { Khan } \\
\text { et al. (2007) }\end{array}$ & IPFP-SC (Human) & $\begin{array}{l}\text { Three patients } \\
\text { (aged } 67,69 \\
\text { and } 72 \text { y.o.) } \\
\text { undergoing } \\
\text { total knee } \\
\text { replacement for } \\
\text { osteoarthritis }\end{array}$ & $\begin{array}{l}\text { DMEM supplemented with } 20 \%(\mathrm{v} / \mathrm{v}) \\
\mathrm{FCS}, 100 \mathrm{U} / \mathrm{ml} \text { penicillin and } 100 \mu \mathrm{g} / \mathrm{ml} \\
\text { streptomycin, with } 2 \mathrm{mM} \text { l-glutamine at } \\
37^{\circ} \mathrm{C} \text { in a humidified } 5 \% \mathrm{CO}_{2} \text { atmosphere }\end{array}$ & $\begin{array}{l}\text { Hypoxia (oxygen } \\
\text { tension } 5 \% \text { ) }\end{array}$ & $\begin{array}{l}\text { Normoxia (oxygen } \\
\text { tension } 20 \% \text { ) }\end{array}$ & 14 days & 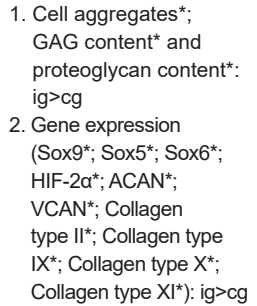 \\
\hline
\end{tabular}


Table 1: (Continued)

\begin{tabular}{|c|c|c|c|c|c|c|c|}
\hline Author & Type of MSC (Donor) & $\begin{array}{l}\text { Donor } \\
\text { characteristics }\end{array}$ & Cells preparation & $\begin{array}{l}\text { Intervention to the } \\
\text { main group }\end{array}$ & Control(s) & Duration & Scores/Results \\
\hline $\begin{array}{l}\text { Khan } \\
\text { et al. (2010) }\end{array}$ & BM-MSC (Human) & $\begin{array}{l}\text { The bone } \\
\text { marrow was } \\
\text { extracted } \\
\text { following } \\
\text { fully informed } \\
\text { consent of } \\
\text { three } 18-40 \text { y.o. } \\
\text { patients }\end{array}$ & $\begin{array}{l}\text { MSC media supplemented with } 5 \mathrm{ng} / \\
\mathrm{mL} \text { rh-FGF-2 at a density of } 166,000 \\
\text { cells per } \mathrm{cm} \text { in a T25 cell culture flask. } \\
\text { Nonadherant cells were removed after } \\
24 \text { h by washing twice in Dulbecco's } \\
\text { phosphate buffered saline (DPBS) and } \\
\text { changing the medium }\end{array}$ & $\begin{array}{l}\text { Hypoxia (oxygen } \\
\text { tension } 5 \% \text { ) }\end{array}$ & $\begin{array}{l}\text { Normoxia (oxygen } \\
\text { tension } 20 \% \text { ) }\end{array}$ & 14 days & 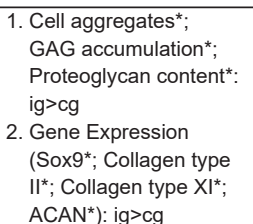 \\
\hline $\begin{array}{l}\text { Kishimoto } \\
\text { et al. (2009) }\end{array}$ & $\begin{array}{l}\text { ATDC5 Cell/ } \\
\text { Chondroproenitor } \\
\text { Cells derived from } \\
\text { murine embryonic } \\
\text { carcinoma (Murine) }\end{array}$ & $\begin{array}{l}\text { RIKEN cell } \\
\text { Bank (Tsukuba, } \\
\text { Japan) }\end{array}$ & $\begin{array}{l}1: 1 \text { mixture of DMEM and Ham's } \\
\mathrm{F}-12 \text { (Invitrogen) supplemented with } \\
5 \% \mathrm{FBS} \text { and antibiotics (Invitrogen: } \\
\text { penicillin } 50 \mathrm{U} / \mathrm{ml} \text {, streptomycin } \\
50 \mathrm{mg} / \mathrm{ml} \text {; Expansion medium) at } 37^{\circ} \mathrm{C} \text { in } \\
\text { a humidified } 5 \% \mathrm{CO}_{2} \text { atmosphere }\end{array}$ & $\begin{array}{l}\text { Hypoxia (oxygen } \\
\text { tension } 1 \% \text { ) }\end{array}$ & $\begin{array}{l}\text { Normoxia (oxygen } \\
\text { tension } 20 \% \text { ) }\end{array}$ & 7 days & $\begin{array}{l}\text { 1. Gene expression (sox9; } \\
\text { HIF-1a): ig=cg } \\
\text { 2. Cell expansion: ig=cg } \\
\text { 3. Increment } \\
\text { Chondrogenic matrix } \\
\text { (BMP4; ITS+; ACAN; } \\
\text { Col2a1): ig=cg }\end{array}$ \\
\hline $\begin{array}{l}\text { Koay } \\
\text { et al. (2008) }\end{array}$ & ESC (Human) & $\begin{array}{l}\text { The National } \\
\text { Institutes of } \\
\text { Health (NIH)- } \\
\text { approved H9 } \\
\text { line (WiCell, } \\
\text { Madison, } \\
\text { WI, USA) } \\
\text { was cultured } \\
\text { according } \\
\text { to standard } \\
\text { protocols using } \\
\text { a defined } \\
\text { medium (www. } \\
\text { wicell.org) and } \\
\text { a gamma- } \\
\text { irradiated CF-1 } \\
\text { (Charles River } \\
\text { Laboratories, } \\
\text { Wilmington, } \\
\text { MA, USA) } \\
\text { mouse } \\
\text { embryonic } \\
\text { fibroblast (MEF) } \\
\text { feeder layer } \\
\text { on T75 culture } \\
\text { plates (Nunc, } \\
\text { Rochester, } \\
\text { NY, USA). } \\
\text { Frozen ESCs } \\
\text { at passage } \\
33 \text { (p33) } \\
\text { were thawed } \\
\text { according } \\
\text { to standard } \\
\text { protocol and } \\
\text { sub-cultured. }\end{array}$ & $\begin{array}{l}\text { HG-DMEM, } 10^{7}-\mathrm{M} \text { dexamethasone, ITS+ } \\
\text { Premix ( } 6.25-\mathrm{ng} / \mathrm{ml} \text { insulin, } 6.25-\mathrm{mg} \\
\text { transferrin, } 6.25-\mathrm{ng} / \mathrm{ml} \text { selenious acid, } \\
1.25-\mathrm{mg} / \mathrm{ml} \text { bovine serum albumin, and } \\
5.35-\mathrm{mg} / \mathrm{ml} \text { linoleic acid), } \\
40-\mu \mathrm{g} / \mathrm{ml} \mathrm{L-proline,} 50-\mathrm{mg} / \mathrm{ml} \text { ascorbic } \\
\text { acid, } 100-\mathrm{mg} / \mathrm{ml} \text { sodium pyruvate, and } 1 \% \\
\text { FBS at } 5 \% \mathrm{CO}_{2}\end{array}$ & $\begin{array}{l}\text { Hypoxia (oxygen } \\
\text { tension } 2 \% \text { ) }\end{array}$ & $\begin{array}{l}\text { Normoxia (oxygen } \\
\text { tension } 20 \% \text { ) }\end{array}$ & 21,49 days & $\begin{array}{l}\text { 1. Construct diameter*: } \\
\text { ig<cg } \\
\text { 2. Construct thickness*: } \\
\text { ig<cg } \\
\text { 3. Collagen } 1^{*} \text { and } \\
\text { Collagen } 2^{*} \text { : ig >cg } \\
\text { 4. Tensile strength; } \\
\text { compressive property; } \\
\text { and relaxed moduli*: } \\
\text { ig }>\text { cg }\end{array}$ \\
\hline $\begin{array}{l}\text { Lee et al. } \\
\text { (2013) }\end{array}$ & BM-MSC (Human) & $\begin{array}{l}\text { Three male } \\
\text { Asians with } \\
\text { age ranged } \\
\text { from the third } \\
\text { to fifth decade, } \\
\text { who received a } \\
\text { spine surgery } \\
\text { for spinal } \\
\text { disorders }\end{array}$ & $\begin{array}{l}\text { a-MEM supplemented with } 16.6 \% \mathrm{FBS} \text {, } \\
100 \text { units } / \mathrm{mL} \text { penicillin, } 100 \mathrm{mg} / \mathrm{mL} \\
\text { streptomycin, and } 2 \mathrm{mM} \mathrm{L-glutamine} \mathrm{at} \\
37^{\circ} \mathrm{C}, 5 \% \mathrm{CO}_{2}\end{array}$ & $\begin{array}{l}\text { Hypoxia (oxygen } \\
\text { tension } 1 \% \text { ) }\end{array}$ & $\begin{array}{l}\text { Normoxia (oxygen } \\
\text { tension } 21 \% \text { ) }\end{array}$ & 7,14 days & $\begin{array}{l}\text { 1. Gene expression } \\
\left(\text { Sox9*; Col2a1*; } \text { ACAN*): }^{*} \text { ig }{ }^{*} \text { cg }\right. \\
(\text { Col10a1*; RUNX2*): } \\
\text { ig<cg } \\
\text { 2. Hypoxic culture } \\
\text { suppressed } \\
\text { chondrogenesis- } \\
\text { induced apoptosis } \\
\text { 3. Hypoxic condition } \\
\text { inhibited activation } \\
\text { of caspase-8 and } \\
\text { caspase-3 during } \\
\text { chondrogenesis }\end{array}$ \\
\hline $\begin{array}{l}\text { Lee } \\
\text { et al. } \\
(2015)\end{array}$ & cAMSC (Dog) & $\begin{array}{l}\text { 4-month-old } \\
\text { beagle dogs } \\
(n=5)\end{array}$ & $\begin{array}{l}\text { DMEM supplemented with } 1 \% \text { penicillin } \\
\text { streptomycin and } 10 \% \mathrm{FBS} \text { and } \\
\text { maintained in a humidified incubator at } 5 \% \\
\mathrm{CO}_{2} \text { and } 37^{\circ} \mathrm{C}\end{array}$ & $\begin{array}{l}\text { Hypoxia (oxygen } \\
\text { tension } 5 \% \text { ) }\end{array}$ & $\begin{array}{l}\text { Normoxia (oxygen } \\
\text { tension } 21 \% \text { ) }\end{array}$ & 21 days & $\begin{array}{l}\text { 1. Survival Gene } \\
\text { Expression }\left(\mathrm{HIF}-1 \alpha^{*} \text {; }\right. \\
\text { VEGFA*): ig>cg } \\
\text { 2. Chondrogenic gene } \\
\text { expression }\left(\mathrm{Col} 2 \mathrm{a} 1^{*} \text {; }\right. \\
\left.\text { ACAN }^{*}\right) \text { : ig }>\mathrm{cg}\end{array}$ \\
\hline $\begin{array}{l}\text { Mahyudin } \\
\text { et al. } \\
(2018)\end{array}$ & BM-MSC (Rabbit) & $\begin{array}{l}\text { Bone marrow } \\
\text { of healthy male } \\
\text { New Zealand } \\
\text { rabbit strain }\end{array}$ & $\begin{array}{l}\alpha \text {-MEM with 1-glutamine, without } \\
\text { ribonucleside or deoxyribinucleside; } \\
\text { FBS; } 1 \text { Glutamine, } 200 \mathrm{mM} \text { (Initrogen); } \\
\text { Penicillin } \mathrm{G}(10,000 \text { units } / \mathrm{mL}) \text { and } \\
\text { streptomycin sulfate }(10,000 \mu \mathrm{g} / \mathrm{mL}) \\
\text { in } 0.85 \% \mathrm{NaCl} \text { solution; Ficol-Paque; } \\
\text { Phospate buffered saline (PBS), without } \\
\text { Ca or } \mathrm{Mg}^{2+}, \mathrm{pH} 7.4 \text {; Tripsin }(0.25 \%) \text {-EDTA } \\
4 \mathrm{NA}(0.38 \mathrm{~g} / \mathrm{dL})\end{array}$ & $\begin{array}{l}\text { Hypoxia (oxygen } \\
\text { tension } 1 \% \text { ) }\end{array}$ & $\begin{array}{l}\text { Normoxia (oxygen } \\
\text { tension } 21 \% \text { ) }\end{array}$ & 35 days & 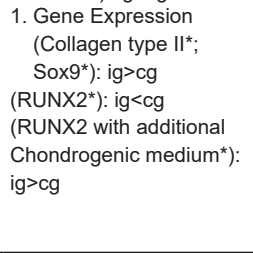 \\
\hline
\end{tabular}


Table 1: (Continued)

\begin{tabular}{|c|c|c|c|c|c|c|c|}
\hline Author & Type of MSC (Donor) & $\begin{array}{l}\text { Donor } \\
\text { characteristics }\end{array}$ & Cells preparation & $\begin{array}{l}\text { Intervention to the } \\
\text { main group }\end{array}$ & Control(s) & Duration & Scores/Results \\
\hline $\begin{array}{l}\text { Markway } \\
\text { et al. (2010) }\end{array}$ & BM-MSC (Human) & $\begin{array}{l}\text { Ten ml bone } \\
\text { marrow was } \\
\text { taken from iliac } \\
\text { crest of healthy } \\
\text { donors }\end{array}$ & $\begin{array}{l}\text { LG-DMEM supplemented with } 10 \% \text { FBS } \\
\text { and } 50 \mu \mathrm{g} / \mathrm{ml} \text { gentamicin and placed in } \\
\text { tissue culture flasks }\end{array}$ & $\begin{array}{l}\text { Hypoxia (oxygen } \\
\text { tension } 2 \% \text { ) }\end{array}$ & $\begin{array}{l}\text { Normoxia (oxygen } \\
\text { tension } 21 \% \text { ) }\end{array}$ & 14 days & $\begin{array}{l}\text { 1. GAG: ig }>\text { cg } \\
\text { 2. Detection of Collagen } \\
1 \text { and Collagen II in } \\
\text { hypoxic cultivation } \\
\text { 3. Gene expression } \\
\left(\text { Sox } 9^{*} ; \text { ACAN }^{*} \text {; Collagen }\right. \\
I^{*} \text {; Collagen II } \text {; Collagen } \\
\left.X^{*} ; \text { RUNX } 2 / \text { CBFA }^{*}\right) \text { : } \\
\text { ig }>\text { cg }\end{array}$ \\
\hline $\begin{array}{l}\text { Merceron } \\
\text { et al. (2010) }\end{array}$ & AMSC (Human) & $\begin{array}{l}\text { Three different } \\
\text { patients } \\
\text { undergoing } \\
\text { abdominal } \\
\text { plastic surgery } \\
\text { who had } \\
\text { provided } \\
\text { prior informed } \\
\text { consent }\end{array}$ & $\begin{array}{l}\text { DMEM containing } 1 \% \text { penicillin- } \\
\text { streptomycin, } 1 \% \text { L-glutamine, and } \\
10 \% \text { FCS (control medium) }\end{array}$ & $\begin{array}{l}\text { Hypoxia (oxygen } \\
\text { tension }<5 \% \text { ) }\end{array}$ & $\begin{array}{l}\text { Normoxia (oxygen } \\
\text { tension } 20 \% \text { ) }\end{array}$ & 28 days & $\begin{array}{l}\text { 1. GAG production } \\
\text { occurred in D7, D14 } \\
\text { and D28 } \\
\text { 2. Gene expression } \\
\left(\text { ACAN*; Col2a1*): }^{*} \text { ig }>\text { cg }\right.\end{array}$ \\
\hline $\begin{array}{l}\text { Meretoja } \\
\text { et al. (2013) }\end{array}$ & $\begin{array}{l}\text { Articular } \\
\text { Chondrocyte } \\
\text { and Bovine-MSC } \\
\text { (Bovine) }\end{array}$ & $\begin{array}{l}\text { Harvested from } \\
7 \text { to } 10 \text { day } \\
\text { old calves and } \\
\text { marrow isolated } \\
\text { from tibiae and } \\
\text { femoral bone of } \\
\text { the bovine }\end{array}$ & $\begin{array}{l}\text { DMEM, } 10 \% \text { FBS, } 1 \% \text { non-essential } \\
\text { amino acids, } 50 \mathrm{mg} / \mathrm{mL} \text { ascorbic acid, } \\
46 \mathrm{mg} / \mathrm{mL} \text { L-proline, } 20 \mathrm{mM} \text { HEPES, } \\
\text { PSF }\end{array}$ & $\begin{array}{l}\text { Hypoxia (oxygen } \\
\text { tension } 5 \% \text { ) }\end{array}$ & $\begin{array}{l}\text { Normoxia (oxygen } \\
\text { tension } 20 \% \text { ) }\end{array}$ & 14 days & $\begin{array}{l}\text { 1. Gene expression } \\
\text { (Collagen II*; CollagenII//*; } \\
\text { Collagen } X) \text { : ig }>c g \\
\left.\text { (Collagen } I^{\star}\right): i g<c g \\
\text { 2. DNA content: ig }=c g \\
\text { 3. Hydroxyproline content: } \\
\quad \text { ig<cg } \\
\text { 4. GAG synthesis: ig }=c g \\
\text { 5. ALP: ig }=c g\end{array}$ \\
\hline $\begin{array}{l}\text { Munir } \\
\text { et al. (2013) }\end{array}$ & $\begin{array}{l}\text { Human AMSC } \\
\text { (Human) }\end{array}$ & $\begin{array}{l}\text { Four human } \\
\text { donors adipose } \\
\text { tissue was } \\
\text { harvested using } \\
\text { a tumescent } \\
\text { technique with } \\
\text { pump-assisted } \\
\text { aspiration. } \\
\text { Subcutaneous } \\
\text { fat were } \\
\text { collected from } \\
\text { one female } \\
\text { and three male } \\
\text { donors, with } \\
\text { fat from the } \\
\text { abdomen and } \\
\text { the hips as the } \\
\text { primary source }\end{array}$ & $\begin{array}{l}\alpha-\text { MEM supplemented with } \\
10 \% \text { FCS in a standard humidified } \\
\text { atmosphere containing } 5 \% \mathrm{CO}_{2} \text { at } 37^{\circ} \mathrm{C}\end{array}$ & $\begin{array}{l}\text { Hypoxia (oxygen } \\
\text { tension } 5 \% \text { ) }\end{array}$ & $\begin{array}{l}\text { Normoxia (oxygen } \\
\text { tension } 21 \% \text { ) }\end{array}$ & 28 days & $\begin{array}{l}\text { 1. Matrix deposition and } \\
\text { higher level of cellularity } \\
\text { occurred peripherally in } \\
\text { hypoxic cultivation } \\
\text { 2. Gene expression } \\
\left(\text { Sox } 9^{*} \text {; Collagen I*; }\right. \\
\text { Collagen II/I Ratio*; } \\
\left.\text { Collagen } X^{*}\right) \text { : ig>cg }\end{array}$ \\
\hline $\begin{array}{l}\text { Ohara } \\
\text { et al. (2016) }\end{array}$ & SDSC (Human) & $\begin{array}{l}\text { Human } \\
\text { synovium was } \\
\text { harvested } \\
\text { during } \\
\text { total knee } \\
\text { arthroplasty } \\
\text { from } 33 \text { donors } \\
\text { diagnosed } \\
\text { with knee } \\
\text { osteoarthritis } \\
\text { and some } \\
\text { synovium were } \\
\text { used for several } \\
\text { experiments } \\
\text { and the } \\
\text { average age } \\
\text { was } 76 \pm 9 \text { years } \\
\text { old }\end{array}$ & $\begin{array}{l}10 \mathrm{~mL} \text { a-MEM containing } 10 \% \mathrm{FBS} \text {, } \\
100 \mathrm{unit} / \mathrm{mL} \text { penicillin and } 100 \mathrm{mg} / \mathrm{ml} \\
\text { streptomycin }\end{array}$ & $\begin{array}{l}\text { Hypoxia (oxygen } \\
\text { tension } 5 \% \text { ) }\end{array}$ & $\begin{array}{l}\text { Normoxia (oxygen } \\
\text { tension } 21 \% \text { ) }\end{array}$ & 14 days & $\begin{array}{l}\text { 1. } C F U: i g=c g \\
\text { 2. mitochondria number } \\
\text { and morphology: ig=cg } \\
\text { 3. GAG: ig=cg } \\
\text { 4. attachment of SDSC: } \\
\text { ig=cg }\end{array}$ \\
\hline $\begin{array}{l}\text { Portron } \\
\text { et al. (2013) }\end{array}$ & $\begin{array}{l}\text { Human AMSC } \\
\text { (Human) Rabbit } \\
\text { AMSC (Rabbit) }\end{array}$ & $\begin{array}{l}\text { Human patients } \\
\text { (hAMSC) } \\
\text { undergoing } \\
\text { liposuction } \\
\text { and who had } \\
\text { given written } \\
\text { consent rAMSC } \\
\text { harvested from } \\
\text { the inguinal } \\
\text { region of the } \\
\text { Rabbit }\end{array}$ & $\begin{array}{l}\text { Serum-free DMEM supplemented with } 1 \% \\
\text { penicillin/streptomycin, } 6.25 \mu \mathrm{g} / \mathrm{mL} \text { insulin, } \\
6.25 \mu \mathrm{g} / \mathrm{mL} \text { transferrin, } 6.25 \mathrm{ng} / \mathrm{mL} \text { sodium } \\
\text { selenite, } 50 \mathrm{nM} \text { sodium L-ascorbate, } \\
10^{8} \mathrm{M} \text { dexamethasone and } 10 \mathrm{ng} / \mathrm{mL} \\
\text { TGF-ß1 with the cultivation in hypoxia } 5 \% \\
\text { and normoxia } 21 \%\end{array}$ & $\begin{array}{l}\text { Hypoxia (oxygen } \\
\text { tension } 5 \% \text { ) }\end{array}$ & $\begin{array}{l}\text { Normoxia (oxygen } \\
\text { tension } 21 \% \text { ) }\end{array}$ & 21 days & $\begin{array}{l}\text { rAMSC: }\left(\text { Col2a } 1^{*} ;\right. \\
\text { ACAN*): ig>cg } \\
\text { hAMSC: }\left(\text { Col2a } 1^{*} ;\right. \\
\left.\text { ACAN }^{*}\right): \text { ig }>c g\end{array}$ \\
\hline $\begin{array}{l}\text { Ranera } \\
\text { et al. (2013) }\end{array}$ & BM-MSC (Horse) & $\begin{array}{l}\text { Bone marrow } \\
\text { aspirates were } \\
\text { obtained from } \\
\text { a total of five } \\
\text { castrated male } \\
\text { horses }\end{array}$ & $\begin{array}{l}\text { The cells were rinsed twice with PBS } \\
\text { (Gibco), counted, and plated at } 2 \times 106 \\
\text { nucleated cells/cm² in } 6 \text {-well plates } \\
\text { (Becton Dickinson) in growth medium } \\
\text { consisting of low glucose Dulbecco's } \\
\text { Modified Eagle's Medium (DMEM, Sigma- } \\
\text { Aldrich) supplemented with } 10 \% \text { Foetal } \\
\text { Bovine Serum, } 1 \% \text { Glutamine (Sigma) and } \\
1 \% \text { Streptomycin/Penicillin. }\end{array}$ & $\begin{array}{l}\text { Hypoxia (oxygen } \\
\text { tension } 5 \% \text { ) }\end{array}$ & $\begin{array}{l}\text { Normoxia (oxygen } \\
\text { tension } 20 \% \text { ) }\end{array}$ & 21 days & 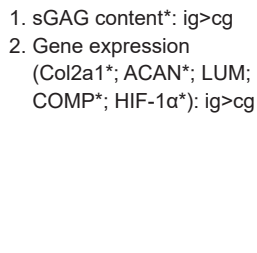 \\
\hline
\end{tabular}


Table 1: (Continued)

\begin{tabular}{|c|c|c|c|c|c|c|c|}
\hline Author & Type of MSC (Donor) & $\begin{array}{l}\text { Donor } \\
\text { characteristics }\end{array}$ & Cells preparation & $\begin{array}{l}\text { Intervention to the } \\
\text { main group }\end{array}$ & Control(s) & Duration & Scores/Results \\
\hline $\begin{array}{l}\text { Silva } \\
\text { et al. (2020) }\end{array}$ & $\begin{array}{l}\text { BM-MSC and SDSC } \\
\text { (Human) }\end{array}$ & $\begin{array}{l}\text { Bone marrow } \\
\text { aspirates } \\
\text { (healthy male } \\
36 \text { years) } \\
\text { were obtained } \\
\text { from Instituto } \\
\text { Português } \\
\text { de Oncologia } \\
\text { Francisco } \\
\text { Gentil, } \\
\text { LisboaPotugal } \\
\text { and an } \\
\text { additional } \\
\text { sample of fresh } \\
\text { unprocessed } \\
\text { bone marrow } \\
\text { sample (Male } \\
24 \text { years) was } \\
\text { purchased from } \\
\text { Lonza (Basel, } \\
\text { Switzerland) } \\
\text { Synovium } \\
\text { aspirates } \\
\text { from donors } \\
\text { undertaking } \\
\text { routine } \\
\text { arthroscopic } \\
\text { surgery with no } \\
\text { history of joint } \\
\text { disease (healthy } \\
\text { male } 22 \text { years } \\
\text { and healthy } \\
\text { male } 28 \text { years) } \\
\text { were obtained } \\
\text { from Centro } \\
\text { Hospitalar } \\
\text { de Lisboa } \\
\text { Ocidental, } \\
\text { E.P.E, Hospital } \\
\text { São Francisco } \\
\text { Xavier, Lisboa, } \\
\text { Portugal }\end{array}$ & $\begin{array}{l}\text { DMEM supplemented with } 10 \% \text { FBS and } \\
1 \% \text { antibiotics (penicillinstreptomycin, } \\
\text { Pen-strep, Gibco) and cryopreserved in } \\
\text { liquid nitrogen tanks until usage }\end{array}$ & $\begin{array}{l}\text { Hypoxia (oxygen } \\
\text { tension } 5 \% \text { ) }\end{array}$ & $\begin{array}{l}\text { Normoxia (oxygen } \\
\text { tension } 21 \% \text { ) }\end{array}$ & 21 days & $\begin{array}{l}\text { 1. Gene expression } \\
\left(\text { Sox9*; } \text { ACAN }^{\star}\right) \\
\text { BM-MSC: ig>cg } \\
\text { SDSC: ig<cg }\end{array}$ \\
\hline $\begin{array}{l}\text { Tian } \\
\text { et al. } \\
\text { (2013) }\end{array}$ & BM-MSC (Human) & $\begin{array}{l}\text { Iliac crests } \\
\text { of } 9 \text { healthy } \\
\text { volunteers } \\
\text { (three males } \\
\text { and five } \\
\text { females) }\end{array}$ & $\begin{array}{l}\text { LG-DMEM supplemented with } 10 \% \mathrm{FBS} \text {, } \\
1 \% \text { penicillin Streptomycin and } 2 \mathrm{mmol} / \mathrm{L} \\
\text { L-glutamine at } 37^{\circ} \mathrm{C} \text { with } 5 \% \mathrm{CO}_{2}\end{array}$ & $\begin{array}{l}\text { Hypoxia (oxygen } \\
\text { tension } 5 \% \text { ) }\end{array}$ & $\begin{array}{l}\text { Normoxia (oxygen } \\
\text { tension } 21 \% \text { ) }\end{array}$ & 21 days & $\begin{array}{l}\text { 1. Gene expression } \\
\left(\mathrm{ACAN}^{*} ; \text { Collagen type }\right. \\
\left.\mathrm{I}^{*}\right): \text { ig }>\mathrm{cg} \\
\text { 2. Diameter } \\
\text { 3. } \mathrm{GA}>\mathrm{Gg} \mathrm{G}^{*}: \mathrm{ig}>\mathrm{cg}\end{array}$ \\
\hline $\begin{array}{l}\text { Wan } \\
\text { Safwani } \\
\text { et al. (2017) }\end{array}$ & AMSC (Human) & $\begin{array}{l}\text { Adipose tissues } \\
\text { were harvested } \\
\text { from } 6 \text { healthy } \\
\text { female donors } \\
\text { aged } 25 \mathrm{e} 35 \\
\text { years who were } \\
\text { undergoing } \\
\text { Caesarean } \\
\text { section with } \\
\text { prior informed } \\
\text { written consent }\end{array}$ & $\begin{array}{l}\text { DMEM/F12 with } 10 \% \text { FBS, } 200 \mu \mathrm{M} \\
\text { indomethacin, } 0.5 \mu \mathrm{M} \text { isobutyl-1-methyl } \\
\text { xanthine, } 1 \mu \mathrm{M} \text { dexamethasone and } \\
10 \mu \mathrm{M} \text { insulin }\end{array}$ & $\begin{array}{l}\text { Hypoxia (oxygen } \\
\text { tension } 2 \% \text { ) }\end{array}$ & $\begin{array}{l}\text { Normoxia (oxygen } \\
\text { tension } 21 \% \text { ) }\end{array}$ & 21 days & $\begin{array}{l}\text { 1. Cell number*: ig }>\mathrm{cg} \\
\text { 2. Gene expression } \\
\left(\mathrm{Col}^{*} ; \text { Sox } 9^{*} ; \mathrm{ACAN}^{\star}\right) \text { : } \\
\text { ig }>\mathrm{cg}\end{array}$ \\
\hline $\begin{array}{l}\text { Xu } \\
\text { et al. (2007) }\end{array}$ & AMSC (Mice) & $\begin{array}{l}\text { The inguinal } \\
\text { fat pads from } \\
\text { 3-week-old } \\
\text { FVB mice } \\
\text { were carefully } \\
\text { dissected } \\
\text { and washed } \\
\text { sequentially } \\
\text { in a Betadine } \\
\text { and phosphate } \\
\text { buffered saline } \\
\text { (PBS) solution. }\end{array}$ & $\begin{array}{l}\text { DMEM, } 1 \% \text { FBS, } 1 \% \text { penicillin/ } \\
\text { streptomycin, } 37.5 \mathrm{mg} / \mathrm{mL} \text { ascorbate- } \\
\text { 2-phophate, ITS premix, and } 10 \mathrm{ng} / \mathrm{mL} \\
\text { TGF-B1 }\end{array}$ & $\begin{array}{l}\text { Hypoxia (oxygen } \\
\text { tension } 2 \% \text { ) }\end{array}$ & $\begin{array}{l}\text { Normoxia (oxygen } \\
\text { tension } 21 \% \text { ) }\end{array}$ & 11 days & $\begin{array}{l}\text { 1. Proliferation rate }{ }^{*} \text { ig }>c g \\
\text { 2. } \mathrm{sGAG} \text { (proteoglycan } \\
\text { accumulation) }^{*}: \text { ig }>\mathrm{cg} \\
\text { 3. Gene expression } \\
\left.\text { (Collagen type } I^{*}\right) \text { : ig>cg } \\
(\text { ACAN; Sox9): ig }=\mathrm{cg}\end{array}$ \\
\hline
\end{tabular}




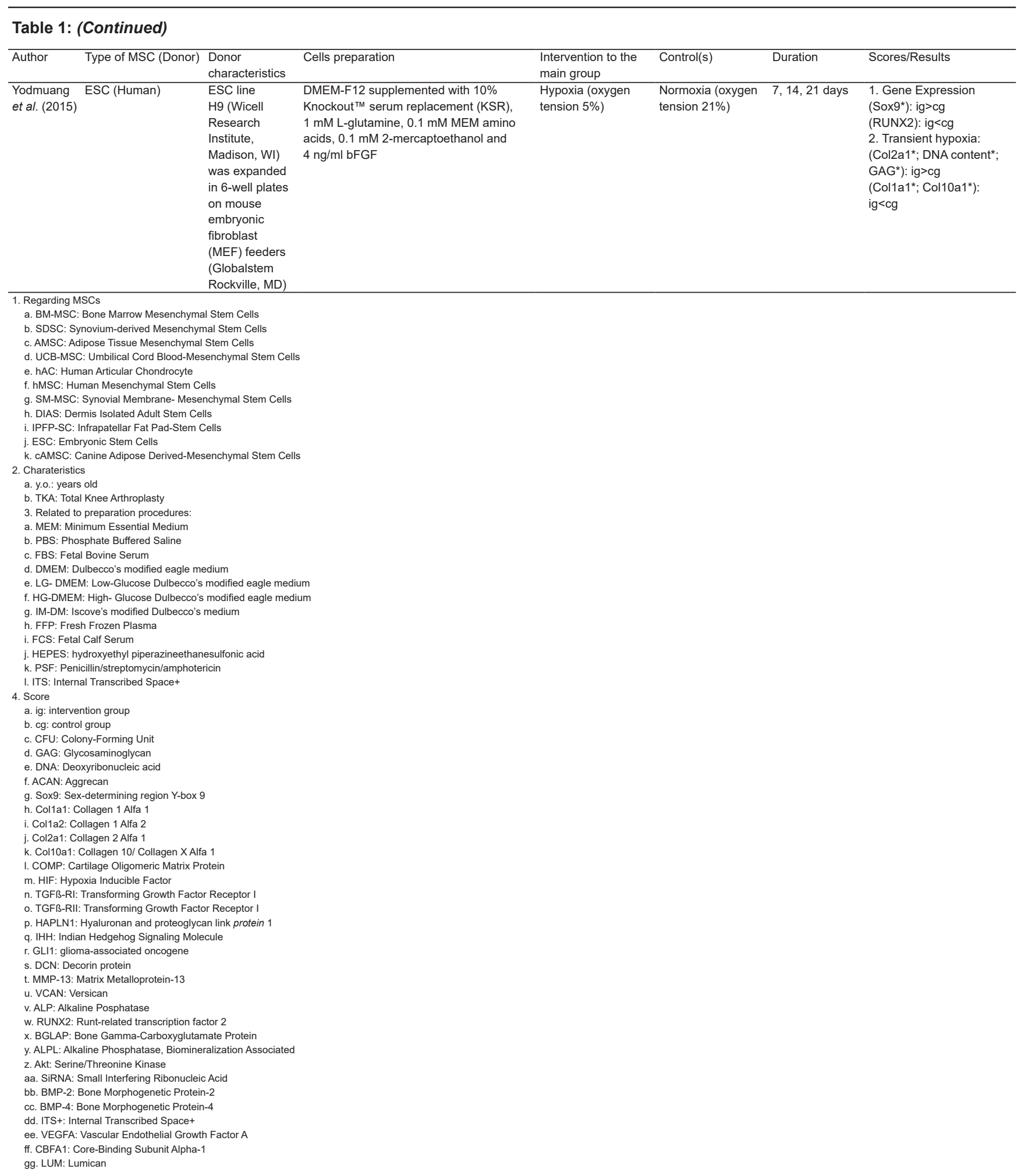

studies [13]. Two authors (R.S. and S.R.) independently performed all the assessments. A thorough discussion was done to resolve discrepancies within authors.

\section{Data extraction and synthesis}

Two authors (R.S. and S.R.) recorded data from all included studies independently to extract the following data: Study design, type of cell donor, control and intervention given, duration of experiment, and result evaluation. Discussion was done to resolve any disagreements between the two authors.

Study outcomes are shown in Table 1. Meta-analysis could not be performed due to the heterogeneity of the data (i.e., source of MSCs, different hypoxic oxygen level, follow-up duration, and outcome measurement). 
Table 2: In vivo study result

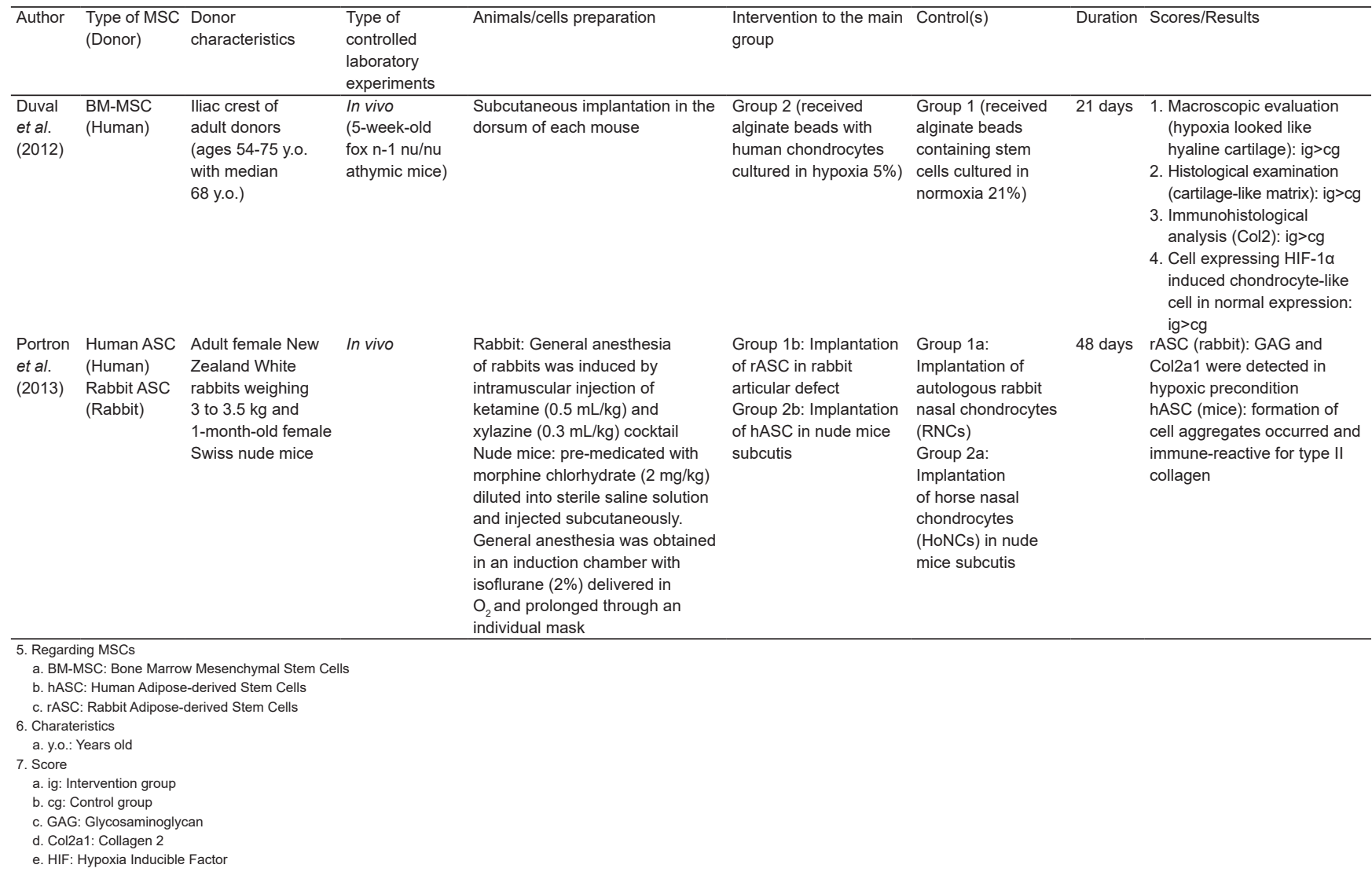

\section{Results}

\section{Study selection}

APRISMA flow diagram (Figure 1) summarizes the study selection process. A total of 438 studies were identified. After screening of the titles and abstracts, 52 articles were considered eligible for further evaluation. After full-text assessment, 34 in vitro studies and two in vivo studies were included in this systematic review.

\section{Study characteristics}

This review is presented in Tables 1 and 2 to specifically explain about the type of MSC used, cell preparation, control and intervention groups, duration of observation, and study results.

Most of the studies utilized stem cells from human (22 studies). Six studies used bovine, murine, and horse stem cells, with two studies for each stem cell type. Human and rabbit, rabbit, mice, rat, goat, and dog were used in the past six studies.

The most common MSC type was from bone marrow (14 studies), followed by AMSC (7 studies), ESC (two studies), and SDSC (two studies). With one study each, the others used BM-MSC and SDSC, UCB-MSC, SM-MSC and BM-MSC, murine MSC, bovine MSC,
hAC/hMSC, DIAS, IPFP-SC, and Chondroprogenitor derived cells.

Hypoxia as intervention group varied from $1 \%$ to $5 \%$ oxygen level compared to normoxia with $21 \%$ oxygen level. Treatment duration varied from 7 to 49 days. Most of studies evaluated chondrogenic gene and protein expression including Col1a1, Col1a2, ACAN, Sox9, COMP, and RUNX2.

\section{In vitro study outcomes}

In vitro study outcomes are summarized in Table 1. According to most studies, there were higher chondrogenic gene and protein expression including ACAN, Col1a1, Col1a2, Col2a1, and Sox9 [5], [9], [10], [11], [14], [15], [16], [17], [18], [19], [20], [21], [22], [23], [24], [25], [26], [27], [28], [29], [30], [31], [32], [33], [34], [35], [36], [37], [38], [39], [40], and higher extracellular matrix including Glycosaminoglycan (GAG) [5], [9], [10], [18], [19], [24], [25], [29], [31], [33], [38], [41], [42], higher expression of HIF- $1 \alpha$ and HIF-2 $\alpha$ [5], [17], [18], [22], [29], [36], [39], GAG production [5], [9], [10], [18], [19], [24], [25], [29], [31], [33], [41] and presence of Transforming Growth Factor-ß (TGF-ß) [5], [9].

The presence of TGF-ß1 and Bone Morphogenetic Protein (BMP)-2 had no effect on chondrogenesis activity [40]. There was no difference between hypoxic and normoxic group in cell surface 
markers including CD13, CD29, CD44, CD73, CD90, CD105, and CD151 [5]. IL-1ß was higher in hypoxic group [37]. Expression of miR-124 [14] and hydroxyproline content [26] was lower in hypoxic group than in normoxic group.

Evaluation of culture size
diameter [10], [31], [37], cell number [32], proliferation rate [33], histological evaluation (collagen type 1 staining) [41], and phosphorylation of Akt [17] was higher in hypoxic group. However, study by Hung et al. stated that the size of pallets and mature chondrocyte morphology was lower in hypoxic group [16]. Kalpakci et al. also stated that cell growth was lower in hypoxic group than normoxic group [41]. Mitochondria number and morphology [43], cell expansion [20], and ALP [26] had no difference in between two groups.

Study by Koay et al. was evaluated for construct diameter and thickness of the cultured cell. The hypoxic group was more inferior to normoxic group. However, the tensile strength, compressive property, and relaxed moduli were found higher than normoxic group [34]. There was inconsistent result in CFU [5], [9], [10], [41], [43]. Adesida et al. and Bae et al. stated that CFU was higher in hypoxic group compared to normoxic group [5], [9]. Ohara et al. stated that there was no CFU difference between normoxic group and hypoxic group [43]. However, Bornes et al. and Kalpakci et al. concluded that there was lower CFU amount in normoxic group compared to hypoxic group [10], [41].

\section{In vivo study outcomes}

In vivo study outcomes are summarized in Table 2. There were only two studies that evaluate in vivo study. Study by Duval et al. revealed that there were superior results in macroscopic evaluation, histological examination, immunohistological analysis, and chondrocyte-like cell induction after HIF-1 $\alpha$ expression in hypoxic group compared to normoxic group [36]. Study by Portron et al. concluded that there were GAG and Col2a1 detection in hypoxic precondition, and formation of cell aggregates for collagen type 2 [28].

\section{Hypoxic condition (oxygen concentration)}

Thirty-four in vitro studies used various oxygen level, 18 studies (52.9\%) used $5 \%$ oxygen, eight studies (23.5\%) used $2 \%$ oxygen, five studies $(14.7 \%$ ) used $1 \%$ oxygen, two studies $(5.9 \%)$ used $3 \%$ oxygen, and one study $(2.9 \%)$ used $2.5 \%$ oxygen (Table 1 ).

Two in vivo studies all used $5 \%$ oxygen concentration (Table 2).

\section{Discussion}

There were many studies that evaluated the chondrogenic genes and proteins. Collagen type II contributes more than $80 \%$ of normal articular cartilage extracellular matrix. It provides tensile strength and cartilaginous scaffold [40]. ACAN is a proteoglycan in articular cartilage that constitutes $80-90 \%$ of all articular cartilage proteoglycan [40]. It serves as fluid regulator in the cartilage matrix and has elastic and compressive strength in articular cartilage [5], [40]. Transcriptional factor Sox9 was found to be an essential factor for chondrogenesis gene including Col2a1 [5]. Collagen type 10 has more osteogenic than chondrogenic differentiation process and also has hypertrophic property marker for chondrocyte [5], [9], [15]. Some studies stated the downregulation and upregulation of this gene. RUNX2 is one of osteogenic mRNA [15]. Expression of Bone Morphogenetic Protein-2 (BMP-2) alone or BMP-2 with TGF- $\beta$ can increase chondrogenesis process [9], [40]. Adesida et al. wrote that there was improvement of TGF- $B$ Receptor II (TGF- $\beta$ RII) significantly and TGF- $\beta$ Receptor I in hypoxic culture condition [5].

Hypoxia state seems to play an important role in chondrocytes proliferation, differentiation, and matrix production [17], [18]. There was no specific consensus for the best hypoxic condition in chondrocyte scaffold culture. In this review, the hypoxic state varied from $1 \%$ to $5 \%$ oxygen level. Most of in vitro studies showed that hypoxic condition can induce production of ACAN, Collagen type II, and Sox9. There was still inconsistent result in improvement of BMP-2, TGF- $\beta$, TGF- $\beta$ RI, TGF- $\beta$ RII, and reduction of Collagen type 10, RUNX2. Most studies that evaluated GAG extracellular matrix showed that there were more production of GAG in hypoxic state of stem cell culture compared to normoxic group [5], [9], [10], [18], [19], [24], [25], [29], [31], [33], [41].

Cell proliferation rate, cell number, cell diameter, and CFU were still unable to be determined due to inconsistent results. Some studies revealed superior result and the others showed inferior result compared to normoxic group. Hypoxic state can induce cartilage formation and chondrocyte proliferation. Normoxic oxygen level state may be stressful to MSC and may induce an oxidative stress response [33].

Based on in vivo studies, there was supportive result in two studies. Portron et al. stated that there was an increment in production of GAG and collagen type II [28]. Study conducted by Duval et al. concluded that there were increments in macroscopic evaluation, histological examination, immunological analysis, and HIF-1 $\alpha$-induced chondrocyte like cell [36]. Low oxygen tension culture before implantation can enhance chondrogenesis in stem cells. These cells produce chondrocyte markers (type II collagen, ACAN) and 
chondrogenesis marker (Sox9) [36]. Hypoxic oxygen level in vitro can influence the regenerative potential of cartilage after in vivo implantation [28]. Chondrogenic stimuli affect stem cells chondrogenesis and cartilage maturation tissue [11], [44].

There were several limitations to this study. The included studies were mostly done with in vitro study with only two studies that reviewed in vivo study. The included studies have several hypoxic oxygen level state, difference in stem cells used, different duration of study evaluation, and different end-point evaluation. Therefore, it was hard to perform a quantitative analysis. Further research is needed to evaluate the exact hypoxic oxygen level that produces the best chondrogenic properties in stem cell culture. More in vivo study is required to achieve better result from further studies.

\section{Conclusion}

Application of hypoxic oxygen level in stem cell culture is a promising method to trigger the chondrogenic lineage differentiation and proliferation. However, more pre-clinical studies are needed to further evaluate the exact hypoxic oxygen level to produce the most supportive environment for stem cell culture.

\section{References}

1. Carballo CB, Nakagawa Y, Sekiya I, Rodeo SA. Basic science of articular cartilage. Clin Sports Med. 2017;36(3):413-25. https:// doi.org/10.1016/j.csm.2017.02.001

PMid:28577703

2. Pruksakorn D, Pothachareoun $P$, Klunklin K, Nimkingratana $P$, Rohanastein $\mathrm{S}$, Padongkiert $\mathrm{S}$, et al. Articular cartilage injury treatment: History and basic science review. Orthop Muscul Syst. 2012;1(4):1-7. https://doi.org/10.4172/2161-0533.1000114

3. Rodriguez-Merchan EC. Articular Cartilage Defects of the Knee. Berlin, Germany: Springer; 2012. p. 1-113.

4. Wang M, Yuan Z, Ma N, Hao C, Guo W, Zou G, et al. Advances and prospects in stem cells for cartilage regeneration. Stem Cells Int. 2017;2017:4130607. https://doi.org/10.1155/2017/4130607 PMid:28246531

5. Adesida AB, Mulet-Sierra A, Jomha NM. Hypoxia mediated isolation and expansion enhances the chondrogenic capacity of bone marrow mesenchymal stromal cells. Stem Cell Res Ther. 2012;3(2):9. https://doi.org/10.1186/scrt100 PMid:22385573

6. Phinney DG, Prockop DJ. Concise review: Mesenchymal stem/multipotent stromal cells: The state of transdifferentiation and modes of tissue repair-current views. Stem Cells. 2007;25(11):2896-902. https://doi.org/10.1634/ stemcells.2007-0637

PMid:17901396
7. Nam Y, Rim YA, Lee J, Ju JH. Current therapeutic strategies for stem cell-based cartilage regeneration. Stem Cells Int. 2018;2018:8490489. https://doi.org/10.1155/2018/8490489 PMid:29765426

8. Mas-Bargues C, Sanz-Ros J, Román-Domínguez A, Inglés M, Gimeno-Mallench L, El Alami M, et al. Relevance of oxygen concentration in stem cell culture for regenerative medicine. Int $J$ Mol Sci. 2019;20(5):1195. https://doi.org/10.3390/ijms20051195 PMid:30857245

9. Bae HC, Park HJ, Wang SY, Yang HR, Lee MC, Han HS. Hypoxic condition enhances chondrogenesis in synoviumderived mesenchymal stem cells. Biomater Res. 2018;22(1):28. https://doi.org/10.1186/s40824-018-0134-x PMid:30275971

10. Bornes TD, Jomha NM, Mulet-Sierra A, Adesida AB. Hypoxic culture of bone marrow-derived mesenchymal stromal stem cells differentially enhances in vitro chondrogenesis within cell-seeded collagen and hyaluronic acid porous scaffolds. Stem Cell Res Ther. 2015;6(1):84. https://doi.org/10.1186/ s13287-015-0075-4 PMid:25900045

11. Huang $X$, Hou $Y$, Zhong L, Huang $D$, Qian $H$, Karperien $M$, et al. Promoted chondrogenesis of co-cultured chondrocytes and mesenchymal stem cells under hypoxia using in situ forming degradable hydrogel scaffolds. Biomacromolecules. 2017;19(1):94-102. https://doi.org/10.1021/acs.biomac.7b01271 PMid:29211452

12. Liberati A, Altman DG, Tetzlaff J, Mulrow C, Gøtzsche PC loannidis JP, et al. The PRISMA statement for reporting systematic reviews and meta-analyses of studies that evaluate health care interventions: Explanation and elaboration. PLoS Med. 2009;6(7):e1000100. https://doi.org/10.1371/journal. pmed. 1000100

PMid: 19621070

13. Whiting P, Savovic J, Higgins JP, Caldwell DM, Reeves BC, Shea B, et al. ROBIS: A new tool to assess risk of bias in systematic reviews was developed. J Clin Epidemiol. 2016;69:225-34. https://doi.org/10.1016/j.jclinepi.2015.06.005 PMid:26092286

14. Gong M, Liang T, Jin S, Dai X, Zhou Z, Gao M, et al. Methylationmediated silencing of miR-124 facilitates chondrogenesis by targeting NFATc1 under hypoxic conditions. Am J Transl Res. 2017;9(9):4111-24

PMid:28979686

15. Henrionnet C, Liang G, Roeder E, Dossot M, Wang $H$, Magdalou $\mathrm{J}$, et al. Hypoxia for mesenchymal stem cell expansion and differentiation: The best way for enhancing TGFß-induced chondrogenesis and preventing calcifications in alginate beads. Tissue Eng Part A. 2017;23(17-18):913-22. https://doi.org/10.1089/ten.tea.2016.0426 PMid:28385113

16. Hung SP, Ho JH, Shih YR, Lo T, Lee OK. Hypoxia promotes proliferation and osteogenic differentiation potentials of human mesenchymal stem cells. J Orthop Res. 2012;30(2):260-6. https://doi.org/10.1002/jor.21517 PMid:21809383

17. Kanichai M, Ferguson D, Prendergast PJ, Campbell VA. Hypoxia promotes chondrogenesis in rat mesenchymal stem cells: A role for AKT and hypoxia-inducible factor (HIF)-1 $\alpha$. J Cell Physiol. 2008;216(3):708-15. https://doi.org/10.1002/jcp.21446 PMid:18366089

18. Khan WS, Adesida AB, Hardingham TE. Hypoxic conditions increase hypoxia-inducible transcription factor $2 \alpha$ and enhance chondrogenesis in stem cells from the infrapatellar fat pad of osteoarthritis patients. Arthritis Res Ther. 2007;9(3):R55. https:// 
doi.org/10.1186/ar2211

PMid:17537234

19. Khan WS, Adesida AB, Tew SR, Lowe ET, Hardingham TE. Bone marrow-derived mesenchymal stem cells express the pericyte marker $3 G 5$ in culture and show enhanced chondrogenesis in hypoxic conditions. J Orthop Res. 2010;28(6):834-40. https:// doi.org/10.1002/jor.21043

PMid:20058274

20. Kishimoto KN, Oxford CL, Reddi AH. Stimulation of the side population fraction of ATDC5 chondroprogenitors by hypoxia. Cell Biol Int. 2009;33(12):1222-9. https://doi.org/10.1016/j. cellbi.2009.06.009

PMid:19524690

21. Lee HH, Chang CC, Shieh MJ, Wang JP, Chen YT, Young TH, et al. Hypoxia enhances chondrogenesis and prevents terminal differentiation through PI3K/Akt/FoxO dependent anti-apoptotic effect. Sci Rep. 2013;3:2683. https://doi.org/10.1038/srep02683 PMid:24042188

22. Lee J, Byeon JS, Lee KS, Gu NY, Lee GB, Kim HR, et al. Chondrogenic potential and anti-senescence effect of hypoxia on canine adipose mesenchymal stem cells. Vet Res Commun. 2016;40(1):1-10. https://doi.org/10.1007/s11259-015-9647-0 PMid:26661466

23. Mahyudin F, Utomo DN, Martanto TW, Hidayat AR, Putri LM. Effect of decellularized cartilage bovine scaffold and hypoxic condition on stem cell differentiation to chondrocyte: An in vitro study. J Biomim Biomater Biomed Eng. 2018;35:67-76. https:// doi.org/10.4028/www.scientific.net/jbbbe.35.67

24. Markway BD, Tan GK, Brooke G, Hudson JE, Cooper-White JJ, Doran MR. Enhanced chondrogenic differentiation of human bone marrow-derived mesenchymal stem cells in low oxygen environment micropellet cultures. Cell Transplant. 2010;19(1):29-42. https://doi.org/10.3727/096368909x478560 PMid: 19878627

25. Merceron C, Vinatier C, Portron S, Masson M, Amiaud J, Guigand L, et al. Differential effects of hypoxia on osteochondrogenic potential of human adipose-derived stem cells. Am J Physiol Cell Physiol. 2010;298(2):355-64. https:// doi.org/10.1152/ajpcell.00398.2009

PMid:19940068

26. Meretoja VV, Dahlin RL, Wright S, Kasper FK, Mikos AG. The effect of hypoxia on the chondrogenic differentiation of co-cultured articular chondrocytes and mesenchymal stem cells in scaffolds. Biomaterials. 2013;34(17):4266-73. https://doi. org/10.1016/j.biomaterials.2013.02.064

PMid:23489925

27. Munir S, Foldager CB, Lind M, Zachar V, Søballe K, Koch TG. Hypoxia enhances chondrogenic differentiation of human adipose tissue-derived stromal cells in scaffold-free and scaffold systems. Cell Tissue Res. 2014;355(1):89-102. https://doi. org/10.1007/s00441-013-1732-5

PMid:24178804

28. Portron S, Merceron C, Gauthier O, Lesoeur J, Sourice S, Masson $\mathrm{M}$, et al. Effects of in vitro low oxygen tension preconditioning of adipose stromal cells on their in vivo chondrogenic potential: Application in cartilage tissue repair. PLoS One. 2013;8(4):e62368. https://doi.org/10.1371/journal. pone.0062368

PMid:23638053

29. Ranera B, Remacha AR, Álvarez-Arguedas S, Castiella T, Vázquez FJ, Romero $A$, et al. Expansion under hypoxic conditions enhances the chondrogenic potential of equine bone marrow-derived mesenchymal stem cells. Vet J. 2013;195(2):248-51. https://doi.org/10.1016/j.tvjl.2012.06.008 PMid:22771146
30. Silva JC, Han X, Silva TP, Xia K, Mikael PE, Cabral JMS, et al. Glycosaminoglycan remodeling during chondrogenic differentiation of human bone marrow-/synovial-derived mesenchymal stem/stromal cells under normoxia and hypoxia. Glycoconj J. 2020;37(3):345-60. https://doi.org/10.1007/ s10719-020-09911-5

PMid:32086666

31. Tian HT, Zhang B, Tian Q, Liu Y, Yang SH, Shao ZW. Construction of self-assembled cartilage tissue from bone marrow mesenchymal stem cells induced by hypoxia combined with GDF-5. J Huazhong Univ Sci Technolog Med Sci. 2013;33(5):700-6. https://doi.org/10.1007/s11596-013-1183-y PMid:24142723

32. Wan Safwani WK, Choi JR, Yong KW, Ting I, Mat Adenan NA, Pingguan-Murphy B. Hypoxia enhances the viability, growth and chondrogenic potential of cryopreserved human adiposederived stem cells. Cryobiology. 2017;75:91-9. https://doi. org/10.1016/j.cryobiol.2017.01.006

PMid:28108309

33. Xu Y, Malladi P, Chiou M, Bekerman E, Giaccia AJ, Longaker MT. In vitro expansion of adipose-derived adult stromal cells in hypoxia enhances early chondrogenesis. Tissue Eng. 2007;13(12):2981-93. https://doi.org/10.1089/ten.2007.0050 PMid: 17916040

34. Koay EJ, Athanasiou KA. Hypoxic chondrogenic differentiation of human embryonic stem cells enhances cartilage protein synthesis and biomechanical functionality. Osteoarthritis Cartilage. 2008;16(12):1450-6. https://doi.org/10.1016/j. joca.2008.04.007

PMid: 18541445

35. Cicione C, Muiños-López E, Hermida-Gómez T, FuentesBoquete I, Díaz-Prado S, Blanco FJ. Effects of severe hypoxia on bone marrow mesenchymal stem cells differentiation potential. Stem Cells Int. 2013;2013:232896. https://doi. org/10.1155/2013/232896

PMid:24082888

36. Duval E, Baugé C, Andriamanalijaona $R$, Bénateau $H$, Leclercq S, Dutoit $S$, et al. Molecular mechanism of hypoxiainduced chondrogenesis and its application in in vivo cartilage tissue engineering. Biomaterials. 2012;33(26):6042-51. https:// doi.org/10.1016/j.biomaterials.2012.04.061

PMid:22677190

37. Felka T, Schäfer R, Schewe B, Benz K, Aicher WK. Hypoxia reduces the inhibitory effect of $\mathrm{LL}-1$ beta on chondrogenic differentiation of FCS-free expanded MSC. Osteoarthritis Cartilage. 2009;17(10):1368-76. https://doi.org/10.1016/j. joca.2009.04.023

PMid:19463979

38. Gale AL, Mammone RM, Dodson ME, Linardi RL, Ortved KF. The effect of hypoxia on chondrogenesis of equine synovial membrane-derived and bone marrow-derived mesenchymal stem cells. BMC Vet Res. 2019;15(1):201. https://doi. org/10.1186/s12917-019-1954-1

PMid:31200719

39. Galeano-Garces C, Camilleri ET, Riester SM, Dudakovic A, Larson DR, Qu W, et al. Molecular validation of chondrogenic differentiation and hypoxia responsiveness of platelet-lysate expanded adipose tissue-derived human mesenchymal stromal cells. Cartilage. 2016;8(3):283-99. https://doi. org/10.1177/1947603516659344

PMid:28618870

40. Gómez-Leduc $T$, Desancé $M$, Hervieu $M$, Legendre $F$, Ollitrault D, de Vienne C, et al. Hypoxia is a critical parameter for chondrogenic differentiation of human umbilical cord blood mesenchymal stem cells in Type I/III collagen sponges. Int J Mol Sci. 2017;18(9):1933. https://doi.org/10.3390/ijms18091933 
PMid:28885597

41. Kalpakci KN, Brown WE, Hu JC, Athanasiou KA. Cartilage tissue engineering using dermis isolated adult stem cells: The use of hypoxia during expansion versus chondrogenic differentiation. PLoS One. 2014;9(5):e98570. https://doi.org/10.1371/journal. pone. 0098570

PMid:24867063

42. Yodmuang S, Marolt D, Marcos-Campos I, Gadjanski I, VunjakNovakovic G. Synergistic effects of hypoxia and morphogenetic factors on early chondrogenic commitment of humanembryonic stem cells in embryoid body culture. Stem Cell Rev Rep. 2015;11(2):22841. https://doi.org/10.1007/s12015-015-9584-x

PMid:25618295
43. Ohara T, Muneta T, Nakagawa $\mathrm{Y}$, Matsukura $\mathrm{Y}$, Ichinose $\mathrm{S}$, Koga $\mathrm{H}$, et al. Hypoxia enhances proliferation through increase of colony formation rate with chondrogenic potential in primary synovial mesenchymal stem cells. J Med Dent Sci. 2016;63(4):61-70.

PMid:28049938

44. Angele P, Yoo JU, Smith C, Mansour J, Jepsen KJ, Nerlich M, et al. Cyclic hydrostatic pressure enhances the chondrogenic phenotype of human mesenchymal progenitor cells differentiated in vitro. J Orthop Res. 2003;21(3):451-7. https:// doi.org/10.1016/s0736-0266(02)00230-9

PMid:12706017 